\title{
Hybrid Maturity Influence on Maize Yield and Yield Component Response to Plant Population in Croatia and Nebraska
}

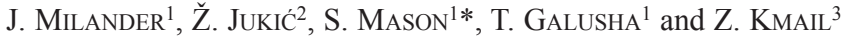 \\ ${ }^{1}$ Department of Agronomy \& Horticulture, University of Nebraska, Lincoln, NE, USA \\ ${ }^{2}$ Department of Field Crops, Forage and Grassland, Faculty of Agriculture, University of Zagreb, \\ Zagreb, Croatia \\ ${ }^{3}$ Department of Statistics, University of Nebraska, Lincoln, NE, USA
}

(Received 17 June 2016; Accepted 24 October 2016;

Communicated by T. Harangozó)

\begin{abstract}
Maize (Zea mays L.) yield component analysis is limited. Research was conducted in 2012 and 2013 at Zagreb, Croatia and Mead, Nebraska, United States with the objective to determine the influence of environment, hybrid maturity, and plant population (PP) on maize yield and yield components. Three maturity classes of maize hybrids were produced at five PP ranging from 65,000 to 105,000 plants ha ${ }^{-1}$ under rainfed conditions. Yield, ears $\mathrm{m}^{-2}$, rows ear ${ }^{-1}$, ear circumference, kernels ear ${ }^{-1}$, kernels row $^{-1}$, ear length, and kernel weight were determined. Average yield was $10.7 \mathrm{t} \mathrm{ha}^{-1}$, but was variable for hybrids across PP. The early maturity-hybrids had lesser ear circumference, more kernels ear ${ }^{-1}$, greater ear length, and fewer rows ear ${ }^{-1}$ than mid- and late-maturity hybrids. Kernels ear ${ }^{-1}$ had the highest correlation with yield $(\mathrm{r}=0.47 ; \mathrm{P}<0.01$ for early-maturity hybrids; $\mathrm{r}=0.55 ; \mathrm{P}<0.01$ for the mid- and late-maturity hybrids). Path analysis indicated that ears $\mathrm{m}^{-2}$, kernels ear ${ }^{-1}$ and kernel weight had similar direct effects on yield for early-maturity hybrids $(\mathrm{R}=0.41$ to 0.48$)$ while kernels ear ${ }^{-1}$ had the largest direct effect $(\mathrm{R}=0.58$ versus 0.32 to 0.36 ) for the midand late-maturity hybrids. Rows ear ${ }^{-1}$ had an indirect effects on yield $(\mathrm{R}=0.30$ to 0.33$)$ for all hybrids, while kernels row $^{-1}$ had indirect effect $(\mathrm{R}=0.46)$ on yield for mid- and latematurity hybrids. Yield component compensation was different for early-maturity hybrid than the mid- and late-maturity hybrids, likely due to the proportion of southern dent and northern flint germplasm present in these hybrids.
\end{abstract}

Keywords: maize, yield, yield components, path analysis

Abbreviations: L: location, Y: year, H: hybrid, PP: plant population

\section{Introduction}

Maize (Zea mays L.) yield is determined directly by the interrelated yield components of ears $\mathrm{m}^{-2}$, kernels ear-1, and kernel weight, and indirectly by the secondary yield components of rows ear ${ }^{-1}$, kernels row ${ }^{-1}$, ear length and circumference. Yield components develop sequentially and have compensatory effects (Dofing and Knight 1992). Detailed

\footnotetext{
*Corresponding author; E-mail: smason1@unl.edu
} 
yield component studies using path correlation analysis have been reported for many crops, but few studies have been reported for maize (Agrama 1996; Mohammadi et al. 2003).

Reductions in early developing yield components can be compensated for by increasing later occurring yield components (Dofing and Knight 1992). Early-season growing conditions influence the number of ears $\mathrm{m}^{-2}$ (or ears plant ${ }^{-1}$ ) (Evans et al. 2003), while midseason (mid-vegetative to mid-grain fill stages) growing conditions tend to influence the number of kernels ear-1 (Abendroth et al. 2011). The potential number of kernels ear-1 is a result of the number of rows ear ${ }^{-1}$ and kernels row $^{-1}$ and is determined between the $\mathrm{V} 7$ to V16 (7 to 16 leaf collars visible) growth stages. The number of rows ear ${ }^{-1}$ is determined at V7 stage shortly after the ear is initiated, and is strongly related to genetics but can also be influenced by environmental stress (Svečnjak et al. 2006; Abendroth et al. 2011). Pollination is the growth stage most sensitive to water and heat stress that can reduce the number of kernels ear-1 (Westgate et al. 2004). Kernel abortion can occur during early grain fill and can reduce kernel number (Westgate et al. 2004; Abendroth et al. 2011). Late-season conditions influence kernel weight as this is determined at physiological maturity (Novacek et al. 2013). A stressful environment during grain fill can result in low kernel weights while increased kernel weight occurs with high irradiance and long grain-fill duration (Abendroth et al. 2011; Novacek et al. 2013, 2014).

Maize hybrid yield response to increasing PP above $60,000 \pm 3000$ plants ha ${ }^{-1}$ is inconsistent across locations, soil types, and hybrids (Reeves and Cox 2013; Milander et al. 2016). Maize hybrid yield often follow quadratic (Novacek et al. 2013, 2014) or quadratic-plateau models (Hammer et al. 2009). Several studies have shown maize hybrid yield and yield component differences in response to PP (Bavec and Bavec 2002; Reeves and Cox 2013), but the basis for these differences is unknown. They are likely related to different ear characteristics associated with germplasm sources. Dent maize hybrids in the United States were developed by hybridization of southern dent with northern flint germplasm (Doebley et al. 1988). The southern dent maize germplasm is characterized by ears with up to 24 rows of deep kernels, commonly with relatively short, girthy ears (Brown and Anderson 1948). Northern flint germplasm has been used in developing early-maturity maize hybrids and is characterized by production of multiple ears per plant, and long, slender ears with 8 to 10 rows per ear of broad and shallow kernels (Brown and Anderson 1947). The objective of this research was to determine the influence of maize hybrid (especially relative maturity) across a range of PP and environments on yield and yield components.

\section{Materials and Methods}

Field experiments were conducted in 2012 and 2013 in rainfed environments at the Faculty of Agriculture, University of Zagreb Experimental Station in Zagreb, Croatia and at the University of Nebraska Agriculture Research and Development Center (ARDC) near Mead, Nebraska, United States. The predominant soil type in Croatia was an unnamed silt loam (typic, Udifluvent) and in Nebraska was Tomek silt loam (fine, smectitic, mesic, 
Pachic, Argiudoll) with 0 to $1 \%$ slope. Winter wheat (Triticum aestivum L.) was the previous crop in Croatia and soybean (Glycine max L. Merr.) in Nebraska. Plots were planted on 27 April 2012 and 30 April 2013 in Croatia and on 5 May 2012 and 7 May 2013 in Nebraska.

Recommended fertilizer application rates were used and production practices at both locations included conventional disk tillage before planting, and pre-emergent and postemergent herbicides combined with cultivation for weed control. Row spacing was $70 \mathrm{~cm}$ in Croatia and $76 \mathrm{~cm}$ in Nebraska.

The experiments were conducted in a randomized complete block design with 3 replications. A factorial combination of three maize hybrids nested within location and five PP were used. Hybrids were selected based upon having similar genetics, maturity classification, and significant commercial production area in Croatia and Nebraska. Hybrids with transgenes were used in Nebraska, while similar hybrids without transgenes were used in Croatia (Table 1). PP of 65,000, 75,000, 85,000, 95,000 and 105,000 plants ha ${ }^{-1}$ were used in both locations. Desired PP was achieved by overplanting and thinning at the V3 to V4 growth stages (Abendroth et al. 2011). Plots were four rows (2.8 m wide) by $6 \mathrm{~m}$ long in Croatia and six rows wide ( $4.6 \mathrm{~m}$ wide) by $9.1 \mathrm{~m}$ long in Nebraska. In Nebraska due to the extremely hot and dry 2012 growing season, $100 \mathrm{~mm} \mathrm{ha}^{-1}$ of irrigation was furrow-applied at the blister growth stage (R2) on 17 July to reduce drought stress and approximate average growing conditions (Supplementary seasonal climatic conditions*).

Grain yield data was measured by mechanically harvesting the middle three rows of the plots in Nebraska and the middle two rows in Croatia at approximately $200 \mathrm{~g} \mathrm{~kg}^{-1}$ water content. Grain was weighed, water content was measured, and yield for each plot adjusted to a water content of $155 \mathrm{~g} \mathrm{~kg}^{-1}$. Prior to harvest, the number of ears was count-

Table 1. DuPont Pioneer maize hybrid characteristics planted for studies in Croatia and Nebraska

\begin{tabular}{|l|c|c|c|c|c|c|}
\hline \multirow{2}{*}{ Hybrid characteristics } & \multicolumn{3}{|c|}{ Maize hybrids in Croatia } & \multicolumn{3}{c|}{ Maize hybrids in Nebraska } \\
\cline { 2 - 7 } & P35F38 & P34N43 & P34B23 & P35F40 & P0876HR & P1151HR \\
\hline GDUs to flowering & 694 & 739 & 755 & 694 & 705 & 733 \\
\hline $\begin{array}{l}\text { GDUs }{ }^{\dagger} \text { to physiological } \\
\text { maturity }\end{array}$ & 1389 & 1444 & 1461 & 1389 & 1432 & 1432 \\
\hline $\begin{array}{l}\mathrm{CRM}^{\ddagger} \text { (days) to harvest } \\
\text { maturity }\end{array}$ & 103 & 107 & 110 & 105 & 108 & 111 \\
\hline Estimated FAO maturity & 520 & 580 & 630 & 550 & 600 & 650 \\
\hline $\begin{array}{l}\text { General maturity } \\
\text { classification }\end{array}$ & Early & Mid & Late & Early & Mid & Late \\
\hline $\begin{array}{l}\text { Presence of transgene } \\
\text { traits }\end{array}$ & None & None & None & $\begin{array}{c}\text { Liberty Link; } \\
\text { Roundup } \\
\text { Ready 2 }\end{array}$ & $\begin{array}{c}\text { Herculex 1; } \\
\text { Liberty Link; } \\
\text { Roundup } \\
\text { Ready 2 }\end{array}$ & $\begin{array}{c}\text { Herculex 1; } \\
\text { Roundup } \\
\text { Ready 1 }\end{array}$ \\
\hline
\end{tabular}

$\dagger \mathrm{GDU}=$ Growing degree unit using $10^{\circ} \mathrm{C}$ base temperature.

${ }^{\star} \mathrm{CRM}=$ Comparative relative maturity.

*Further details about the Electronic Supplementary Material (ESM) can be found at the end of the article. 
ed to determine the number of ears $\mathrm{m}^{-2}$. Six consecutive-ear samples were collected from each plot and used to measure the yield components. Primary and secondary yield components measured were rows ear ${ }^{-1}$, ear circumference, kernels ear ${ }^{-1}$, kernels row $^{-1}$, ear length, and kernel weight. Rows ear ${ }^{-1}$, kernels row $^{-1}$ and kernels ear ${ }^{-1}$ were hand counted, and ear length and middle-of-the ear circumference were measured prior to hand shelling. The number of kernels ear ${ }^{-1}$ was hand counted, 100 kernels were randomly selected from each ear, weighed, and weight adjusted to a water content of $155 \mathrm{~g} \mathrm{~kg}^{-1}$.

Data were analyzed using PROC Mixed of SAS (SAS Institute 2014). Analysis of variance was conducted with location $(\mathrm{L})$, year $(\mathrm{Y})$, hybrid (Location) $[\mathrm{H}((\mathrm{L})]$, and PP (P) main effects and their interactions considered fixed effects. Pair-wise comparisons were used for mean separation. Analysis of variance indicated that yield and yield components of the early-maturity hybrids responded differently to PP than the mid- and latematurity hybrids, thus Pearson correlations and path analysis were conducted separately. Pearson correlations were calculated to identify interrelationships among measured parameters, and path correlation analysis (Agrama 1996; Mohammadi et al. 2003) of yield and the primary and secondary yield components was completed using PROC CALIS to determine model goodness-of-fit. PP responses from this study have been reported previously in Milander et al. (2016), while this article reports the hybrid maturity effects on maize yield and components.

\section{Results}

\section{Yield and yield components}

Hybrid interaction with $\mathrm{PP} H(\mathrm{~L}) \times \mathrm{PP}$ interaction effect were present for yield and number of ears $\mathrm{m}^{-2}$ (Table S1). The $\mathrm{H}(\mathrm{L}) \times \mathrm{P}$ interaction indicated that maize yield was not influenced by PP in four-out-of-six hybrid-location combinations. However, the mid-maturity P34N43 hybrid in Croatia reduced yield linearly with increasing PP $(y=14.199-0.446 x$; $\left.\mathrm{R}^{2}=0.85 ; \mathrm{P}<0.01\right)$ and for the late-maturity hybrid P1151HR in Nebraska increased yield quadratically with increasing PP $\left(y=-15.794+0.7343 x-0.0047 x^{2} ; R^{2}=0.99\right.$; $\mathrm{P}<0.01$ ) to approximately 80,000 plants $\mathrm{ha}^{-1}$. In Croatia, the late-maturity hybrid P34B23 produced fewer ears $\mathrm{m}^{-2}$ than the early- and mid-maturity hybrids P35F38 and P34N43 (Table 2), while there was no difference among hybrids in Nebraska.

The number of rows ear ${ }^{-1}$ was effected by the $\mathrm{H}(\mathrm{L}) \times \mathrm{PP}$ interaction (Table S1). This interaction indicated that number of rows ear ${ }^{-1}$ was not influenced by PP in three-out-ofsix hybrid-location combinations. However, the mid-maturity P34N43 ( $\mathrm{y}=21.819-$ $0.0658 x ; r=0.91 ; P=0.01)$ and late-maturity P34B23 $(y=21.346-0.0670 x ; r=0.91$; $\mathrm{P}=0.01)$ hybrids in Croatia and the mid-maturity P0876HR $(\mathrm{y}=17.727-0.0202 \mathrm{x}$; $\mathrm{r}=0.84 ; \mathrm{P}<0.01$ ) hybrid in Nebraska had a linear decrease in the number of rows ear ${ }^{-1}$ with increasing PP. In Croatia, the early-maturity P35F38 hybrid had a smaller ear circumference than the mid-maturity P34N43 hybrid (Table 3), while in Nebraska the earlymaturity P35F40 hybrid had smaller ear circumference than the late-maturity P1151HR hybrid. Maize produced $1.6 \mathrm{~cm}$ shorter ears in Croatia than in Nebraska. 

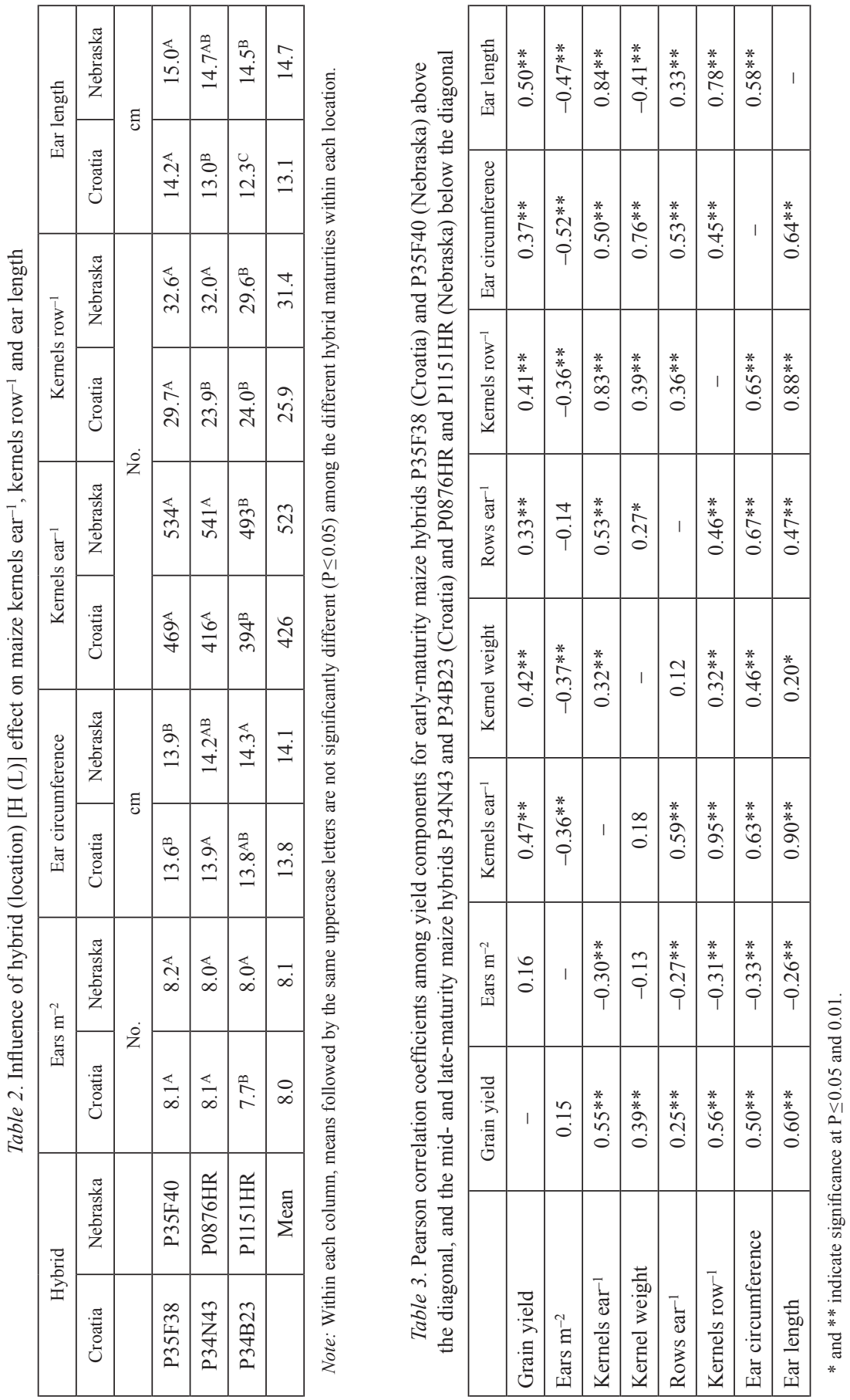
An H (L) effect was also found for kernels ear ${ }^{-1}$, kernels row ${ }^{-1}$, and ear length (Table S1). The early-maturity P35F40 hybrid produced more kernels ear ${ }^{-1}$, kernels row $^{-1}$ and greater ear length than late-maturity P34B23 hybrid in Croatia (Table 2). In Nebraska, the early-maturity P35F40 hybrid produced more kernels ear ${ }^{-1}$, kernels row ${ }^{-1}$ and greater ear lengths than late-maturity P1151HR hybrid however the mid-maturity P0876HR hybrid produced the highest number of kernels ear ${ }^{-1}$.

The $\mathrm{Y} \times \mathrm{H}(\mathrm{L})$ interaction effect (Table S1) indicated that kernel weights in Croatia for the mid-maturity P34N43 hybrid was 30.0 g per 100-kernel in 2013 and 24.9 g per 100 -kernels in 2012, while no differences were present for other hybrids. In Nebraska, 100-kernel weights were 2.2 to 2.9 g greater for all hybrids in 2013 than in 2012, consistent with the hot, dry growing season in 2012 limiting grain fill. In Croatia, the mid-maturity P34N43 (30.0 g) and late-maturity hybrid P34B23 (29.8 g) had greater 100-kernel weight than for the early-maturity P35F38 hybrid (25.5 g), while in Nebraska, the late maturity P1151HR hybrid had the greatest kernel weights of 32.7 in 2012 (compared to 27.9 and $28 \mathrm{~g}$ ) and 34.9 (compared to 30.3 and $31.5 \mathrm{~g}$ ) in 2013. Kernel weights were 4.7 grams per 100-kernels lower in Croatia than in Nebraska.

\section{Pearson correlations}

Yield components were more highly correlated with grain yield for the mid- and latematurity maize hybrids than for the early-maturity hybrids (Table 3). All yield components except the number of ears $\mathrm{m}^{-2}$ were highly correlated with grain yield, with these correlations being between 0.25 and 0.60 for the mid- and late-maturity hybrids. Rows ear $^{-1}$, kernels row ${ }^{-1}$, ear circumference, and ear length were all highly correlated with kernels ear ${ }^{-1}$ for all hybrids. There was a large negative correlation between ears $\mathrm{m}^{-2}$ and ear circumference that was greater in the early-maturity than in the late-maturity hybrids. Kernel weight had the highest correlation with ear circumference for both hybrid classes, (Table 3). The number of rows ear ${ }^{-1}$ was highly correlated with ear circumference for all hybrids. Rows ear ${ }^{-1}$ was also positively correlated with kernels row ${ }^{-1}$ and ear length.

\section{Path analysis}

The path analysis models for both the early, and mid- and late-maturity hybrids indicated that the primary yield components of ears $\mathrm{m}^{-2}$, kernels ear ${ }^{-1}$, and kernel weight had positive direct effects on grain yield (Fig. 1A and B), as also found by Agrama (1996). Ears $\mathrm{m}^{-2}$, kernels ear ${ }^{-1}$ and kernel weight had similar magnitude direct effects $\left(\mathrm{R}=0.41^{* *}\right.$ to $\left.0.48^{* *}\right)$ on grain yield for the early-maturity hybrids, while kernels ear ${ }^{-1}$ had larger direct effect $\left(\mathrm{R}=0.58^{* *}\right)$ than ears $\mathrm{m}^{-2}\left(\mathrm{R}=0.36^{* *}\right)$ and kernel weight $(\mathrm{R}=0.32)$ for the midand late-maturity hybrids. Among the primary yield components, ears $\mathrm{m}^{-2}$ had negative indirect effects $\left(\mathrm{R}=-0.09 *\right.$ to $\left.-0.15^{*}\right)$ on grain yield for all hybrids and also kernels $\operatorname{ear}^{-1}\left(\mathrm{R}=-0.37^{* *}\right)$ on grain yield for the mid- and late-maturity hybrids. Path analysis indicated that ears $\mathrm{m}^{-2}$ had a negative direct effect on kernel weight for the early-maturity hybrids, and rows ear ${ }^{-1}$ for the mid- and late-maturity hybrids. For both early-maturity, 
and mid- and late-maturity maize hybrids, rows ear $^{-1}$ had positive direct effects on kernels ear $^{-1}$ and kernels row ${ }^{-1}$, and these yield components had direct effects on each other. The number of kernels ear-1 also had a large negative direct effect on kernel weight in the midand late-maturity hybrid model. The number of kernels row ${ }^{-1}$ had direct positive effects on kernel weight for both maturity classes $(\mathrm{R}=0.29 *$ for early-maturity hybrids; $\mathrm{R}=1.44 * *$ for the mid-late maturity hybrids), but of a larger magnitude for the mid- and late-maturity hybrids.

\section{Discussion}

Maize hybrid responses to increasing PP was $<2 \mathrm{~T} \mathrm{ha}^{-1}$ and inconsistent across locations and years, as previously reported by Reeves and Cox (2013). Yield component compensation differed with hybrid maturity classification influencing maize yield and yield component responses. Modern maize hybrids developed in the United States are largely a combination of southern dent and northern flint germplasm (Doebley et al. 1988). In mid- and late-maturity hybrids in this study, the southern dent germplasm more evident based on ear characteristics (Brown and Anderson 1948), while the ear characteristics suggested a greater proportion of northern flint germplasm in early-maturity hybrids. Yield components for the early-maturity maize hybrids had more ears $\mathrm{m}^{-2}$, longer ears with smaller circumference than for mid- and late-maturity hybrids consistent with Brown and Anderson (1947) and Svečnjak et al. (2006). Visual observations indicated that kernels were shallower also for the early-maturity hybrids, consistent with the presence of more north-

A) Early-maturity hybrids P35F38 and P35F40 (Chi-square P-value = 0.12; Goodness-of-fit $=0.95$; Root mean square error $\left.=0.11 ; \mathrm{R}^{2}=0.57\right)$.

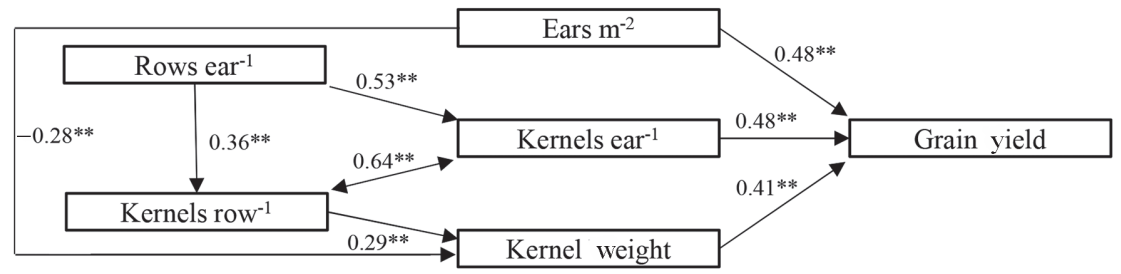

B) Mid- and late-maturity hybrids PP34N43, P34B23, P0876HR, and P1151HR (Chi-square $\mathrm{P}$-value $=0.16 ;$ Goodness-of-fit $=0.98 ;$ Root mean square error $=0.07 ; \mathrm{R}^{2}=0.27$ ).

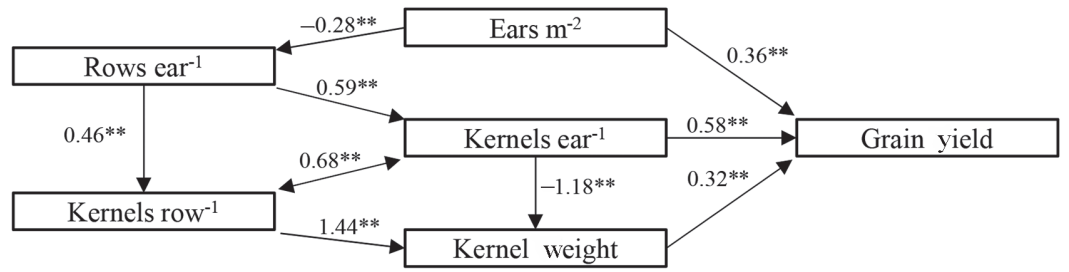

Figure 1. Path analysis models and direct effects for maize grain yield and components 
ern flint germplasm (Brown and Anderson 1947). Relative proportion of different germplasm sources in maize hybrids is important to understanding maize yield component compensation with increasing PP.

Environmental conditions (i.e. location and year) influenced the hybrid response to increasing PP for grain yield, number of rows ear ${ }^{-1}$, and kernel weight. Since Croatia is located at greater latitude than Nebraska, it has a shorter summer growing season, lower seasonal solar radiation, and longer summer days. Mid- and/or late-maturity maize hybrids had decreased number of rows ear ${ }^{-1}$ with increasing PP, but differences were small since the number of rows ear ${ }^{-1}$ is largely genetically controlled (Abendroth et al. 2011). Kernel weights were lower for all maize hybrids in Croatia than in Nebraska, but especially for the late-maturity hybrids. Pearson correlation and path analysis are two methods to help understand yield component compensation and relative importance of yield components in determining yield. Pearson correlations indicated the highly inter-related ear length, number of kernels ear ${ }^{-1}$, and number of kernels row ${ }^{-1}$ were the yield components most associated with maize yield for all hybrids in this study (Table 3), consistent with past research (Agrama 1996; Evans et al. 2003; Cox et al. 2006). The number of ears $\mathrm{m}^{-2}$ was not correlated with yield for all hybrids, and kernel weight, number of rows ear ${ }^{-1}$ and ear circumference had intermediate correlations.

Path analysis provides more detailed analysis of the yield components, by assisting to understand causal relationships, direction of effects on yield and other yield components, and separation of direct and indirect effects. Path analysis of yield components by order helps interpret compensatory effects. Path analysis of the primary yield components for mid- and late-maturity hybrids was similar to the Pearson correlations, with the number of kernels ear ${ }^{-1}$ having the largest direct effect on yield (Fig. 1). However, for the earlymaturity hybrids all the primary yield components of the number of ears $\mathrm{m}^{-2}$, kernels ear $^{-1}$ and kernel weight had similar direct effects on yield, similar to results of Mohammadi et al. (2003). Thus, production of larger numbers of ears $\mathrm{m}^{-2}$ and/or kernels ear ${ }^{-1}$ reduced the later developing yield components that influenced yield. For the early-maturity hybrids, the earlier produced number of ears $\mathrm{m}^{-2}$ had a negative direct effect on kernel weight. In contrast, the number kernels ear ${ }^{-1}$ influenced yield more for the mid- and latematurity hybrids.

Path analysis of primary plus secondary yield components (Fig. 1) were similar except for two major differences: (1) the number of ears $\mathrm{m}^{-2}$ had a negative direct effect on the number of rows ear ${ }^{-1}$ for mid- and late-maturity hybrids with no direct effect being present for early-maturity hybrids, and (2) the mid- and late-maturity hybrids had a much larger direct effect of kernels row ${ }^{-1}$ on kernel weight than for the early-maturity hybrids. These differences were likely due to different germplasm sources related to maturity and the timing of critical growth stages (Westgate et al. 2004; Abendroth et al. 2011). High temperature, low rainfall, and a supplemental irrigation to simulate average growing conditions were factors in 2012 in Nebraska (Supplemental Climate Information). The maize hybrids used for this study likely had germplasm source differences which would have altered yield component responses to PP and environment (Doebley et al. 1988). Hybrid maturity, germplasm source, crowding stress due to PP, and environment all influence 
maize yield components. However, the path analysis of this study indicates the importance of all yield components on yield, especially the number of kernels ear ${ }^{-1}$.

In conclusion, maize hybrid yield responses across PP were variable, and were accounted for through yield component compensation. Early-maturity hybrids had different yield response to PP alteration than other hybrids, and had lesser ear circumference, more kernels row ${ }^{-1}$, and greater ear length. The number of rows for early-maturity hybrids at lower PP was approximately two less than for mid- and late-maturity hybrids. We speculate that the different responses to yield and yield components are related to the use of northern flint germplasm in maize breeding programs to obtain earlier maturity. Kernels ear $^{-1}$ had the highest Pearson correlations with maize yield for all hybrids in the study, but this association was higher for the mid- and late-maturity hybrids. Path correlation analysis indicated a similar relationship, except that for early-maturity hybrids direct effects were equal for kernels ear ${ }^{-1}$ and ears $\mathrm{m}^{-2}$, and only slightly larger than for kernel weight. Hybrid differences for direct (and indirect) effects on later occurring yield components were dramatically different. The early-maturity hybrids had a large negative direct effect of ears $\mathrm{m}^{-2}$ on kernel weight, while mid- and late-maturity hybrids had a large negative direct effect of kernels ear-1 on kernel weight and ears $\mathrm{m}^{-2}$ on rows ear ${ }^{-1}$, and a large positive direct effect of kernels row $^{-1}$ on kernel weight, and negative indirect effect of ears $\mathrm{m}^{-2}$ on kernels row ${ }^{-1}$. Results in this study demonstrate the importance of yield component compensation among maize hybrids with different maturities across environments and PP to produce relatively consistent yields.

\section{References}

Abendroth, L.J., Elmore, R.W., Boyer, M.J., Marlay, S.K. 2011. Corn Growth and Development. PMR 1009. Iowa State Univ. Ext., Ames, IA, USA.

Agrama, H.A.S. 1996. Sequential path analysis of grain yield and its components in maize. Plant Breeding 115:343-346.

Bavec, F., Bavec, M. 2002. Effects of plant population on leaf area index, cob characteristics and grain yield of early maturing maize cultivars (FAO 100-400). Eur. J. Agron. 16:151-159.

Brown, W.L., Anderson, E. 1947. The northern flint corns. Annuals of the Missouri Botanical Gardens 34:1-8.

Brown, W.L., Anderson, E. 1948. The southern dent corns. Annuals of the Missouri Botanical Gardens 35:255276.

Cox, W.J., Hahn, R.R., Stachowski, P.J. 2006. Time of weed removal with glyphosate affects corn growth and yield components. Agron. J. 98:349-353.

Doebley, J., Wendel, J.D., Smith, J.S.C., Stuber, C.W., Goodman, M.M. 1988. The origin of corn-belt maize: The isozyme evidence. Economic Bot. 42:120-131.

Dofing, S.M., Knight, C.W. 1992. Alternative model for path analysis of small-grain yield. Crop Sci. 32:487489.

Evans, S., Knezevic, S., Lindquist, J., Shapiro, C., Blankenship, E.E. 2003. Nitrogen application influences the critical period for weed control in corn. Weed Sci. 51:408-417.

Hammer, G.L., Dong, Z., McLean, G., Doherty, A., Messina, C., Schussler, J., Zinselmeier, C., Paskiewicz, S., Cooper, M. 2009. Can changes in canopy and/or root system architecture explain historical maize yield trends in the U.S. Corn Belt? Crop Sci. 49:299-312.

Hashemi, A.M., Herbert, S.J., Putnam, D.H. 2005. Yield response of corn to crowding stress. Agron. J. 97:839846 . 
Milander, J.J., Jukic, Z., Mason, S.C., Galusha, T., Kmail, Z. 2016. Plant population influence on maize yield components in Croatia and Nebraska. Crop Sci. 56:2742-2750.

Mohammadi, S.A., Prasanna, B.M., Singh, N.N. 2003. Sequential path model for determining interrelationships among grain yield and related characters in maize. Crop Sci. 43:1690-1697.

Novacek. M.J., Mason, S.C., Galusha, T.D., Yaseen, M. 2013. Twin rows minimally impact irrigated maize yield, morphology, and lodging. Agron. J. 105:268-276.

Novacek. M.J., Mason, S.C., Galusha, T.D., Yaseen, M. 2014. Bt transgenes minimally influence maize grain yields and lodging across plant populations. Maydica 59:90-95.

Reeves, G.W., Cox, W.J. 2013. Inconsistent responses of corn to seeding rates in field-scale studies. Agron. J. 105:693-704

SAS Institute. 2014. SAS/STAT 9.3 User's Guide. SAS Inst., Cary, NC, USA.

Svečnjak, Z., Varga, B., Butorac, J. 2006. Yield components of apical and subapical ear contributing to the grain yield responses of prolific maize at high and low plant populations. J. of Agron. and Crop Sci. 192:37-42.

Westgate, M.E., Otegui, M.E., Andrade, F.H. 2004. Physiology of the corn plant. In: Smith, C.W., Betrán, J., Runge, E.C.A. (eds), Corn: Origin, History, Technology, and Production. John Wiley \& Sons, Inc. Hoboken, NJ, USA. pp. 235-273.

\section{Electronic Supplementary Material (ESM)}

Electronic Supplementary Material (ESM) associated with this article can be found at the website of CRC at http://www.akademiai.com/content/120427/

Electronic Supplementary Seasonal climatic conditions

Electronic Supplementary Table S1. Mean squares and level of probability hybrid and plant population effects on maize grain yield and yield components in Croatia and Nebraska in 2012 and 2013 